\title{
BUSCANDO UN LENGUAJE COMÚN EN EDUCACIÓN: ¿DE QUÉ HABLAMOS CUANDO HABLAMOS DE INTERCULTURALIDAD? ${ }^{1}$
}

\author{
Eduardo S. Vila Merino ${ }^{2}$
}

\begin{abstract}
The use of a common language is essential both for reflection and for practice in education. When we speak and act in the name of interculturality, there is usually/often some confusion about what is or what is not intercultural. For this reason, it is appropriate to deepen our conception of this term, teasing out the different strands for the improvement of theoretical-practical contributions to processes of intercultural vocation.

Keywords: intercultural perspective; Intercultural Education; multiculturalism; Theory of Education
\end{abstract}

Resumen: La necesidad de plantearnos un lenguaje común es fundamental para la reflexión y la práctica educativa. Cuando hablamos y actuamos en nombre de la interculturalidad suele haber confusión entre lo que es o no es intercultural, por lo que parece oportuno hacer un ejercicio de profundización conceptual en este término, desgranando los matices necesarios para la mejora de las aportaciones teórico-prácticas vinculadas a los procesos con vocación intercultural.

Palabras clave: interculturalidad; Educación Intercultural; multiculturalismo, Teoría de la Educación

El presente texto pretende ofrecer una panorámica en torno al concepto de interculturalidad que nos ayude a clarificarlo y, a partir de ahí, poder establecer dinámicas y prácticas educativas coherentes con dicha concepción, alejándonos de los clichés que está teniendo en los últimos años, donde se definen como 'interculturales' pensamientos y acciones que como mucho entrarían en el ámbito del reconocimiento de la realidad multicultural de nuestro contexto social y educativo. En este sentido es necesario apostar por la interculturalidad como un valor, yendo más allá de las medidas de compensación educativa al alumnado de origen inmigrante e insertándose como todo un paradigma que debe impregnar la vida en los centros educativos. Y para ello debemos estar convencidos de la necesidad de construir ciudadanía desde una valoración de la diversidad cultural que no la convierta en diferenciación cultural ni desigualdad social, a la manera que plantea Bhabha:

"La idea de que la diversidad cultural constituye un problema porque ya hay muchas culturas diferentes no es la razón por la que existe la diferencia cultural. La diferencia cultural es un discurso

Vila Merino, E. S. (2011). Buscando un lenguaje común en Educación: ¿De qué hablamos cuando hablamos de interculturalidad? DEDiCA. REVISTA DE EDUCAÇÃO E HUMANIDADES, 1 (2011) Março, 147-158 
elaborado en un momento en el que se están desafiando elementos del poder o la autoridad (...) La diferencia cultural no resulta difícil, si se quiere, por el hecho de que haya diferentes culturas, sino porque existe una cuestión particular sobre la redistribución de los bienes entre las culturas, o los fondos de las culturas, o el surgimiento de minorías o inmigrantes en una situación de recursos -a dónde deben dirigirse estos- 0 la construcción de escuelas y la decisión sobre si la escuela será bilingüe, trilingüe o lo que deba ser. Es en este punto en el que se produce el problema de la diferencia cultural. De este modo, constituye verdaderamente un argumento contra la naturalización de la idea de cultura" (Bhabha, cit. Giroux, 2001: 71).

Esto nos debe hacer sentar las bases para una concepción de la interculturalidad que dé respuesta a nuestras realidades multiculturales y los desafíos de la globalización escapando de su definición neoliberal. Se trata de avanzar hacia una comprensión de la multiculturalidad como interpretación ampliada de la democracia, trascendiendo el multiculturalismo liberal y tolerante que habla retóricamente de lo Otro pero sin su Otredad (Martínez de Bringas, 2007). La interculturalidad aquí, lejos de verse como una categoría abstracta, racional y homogénea, remite más a la confrontación y entrelazamiento polémico de diferentes grupos, comunidades e identidades que entran en conexión e intercambio. Así, mientras que multiculturalidad liberal supone la aceptación teórica de lo heterogéneo; la interculturalidad, en un buceo más profundo y delicado, evidencia que las diferencias son lo que son y se afirman identitariamente a partir de intensas relaciones de negociación y de dialécticas conflictivas desde las cuales podemos intentar desarrollar préstamos recíprocos de significados para la construcción intercultural. Con esto es necesario aclarar también que la interculturalidad tampoco es un tránsito de las diferencias a las fusiones que las diluyen, puesto que los flujos presentes en las realidades multiculturales son conflictivos y hay que saber ubicarse en ellos reconociendo las diferencias desde la lógica de los procesos de producción de condiciones de igualdad/desigualdad, conexión/desconexión, inclusión/exclusión (García Canclini, 2005) como referentes claros a la hora de abordar la construcción intercultural.

Desde el ámbito educativo, por tanto, el proceso intercultural está íntimamente ligado a la perspectiva de los derechos humanos y nos plantea como exigencia ética la búsqueda de códigos y puentes de conexión comunes y recíprocos a todas las identidades y 
cosmovisiones en interacción y/o conflicto, de manera que éstos nos sirvan para el contraste y crítica de los mecanismos culturales presentes y, a partir de ahí, para establecer pautas de traducción plausibles desde las distintas ópticas culturales implicadas como condición de posibilidad para la convivencia. De esta forma, la presencia y la relación con el otro u otra y su otredad nos puede ayudar a transformar el 'choque de civilizaciones' en un 'encuentro de vecinos' (Bauman, 2007). Pero eso sí, la propia interculturalidad debe aquí asumir la condición inconmensurable de ciertos enunciados culturales, los cuales no es posible codificar en un lenguaje de mediación intercultural en determinados contextos. Se trata entonces de contrastar la gramática de la interculturalidad asumiendo la dificultad y las limitaciones del propio proceso intercultural cuando las condiciones del conflicto cultural lo hacen insensible a la traducción. Ahí es donde la interculturalidad debe resituarse como elemento fundamental para el acceso a un posible pacto cultural que recree las condiciones para la convivencia. Por eso se hace necesario para la interculturalidad el llevar a cabo análisis de los procesos de las diferencias y las causas estructurales que generan dinámicas de desigualdad en recursos y capacidades en contextos concretos, de falta de reconocimiento para determinadas identidades personales y/o colectivas, de desconexión selectiva de posibilidades comunicacionales y de bienestar que lleva a la exclusión. Ello exige evitar una construcción meramente victimista de los/las excluidos/as-oprimidos/as, perversión tan propia del multiculturalismo liberal, y superar una comprensión esencialista y dogmática de la alteridad que la aleja del sujeto (Martínez de Bringas, 2007).

Frente a esto, una concepción de interculturalidad como la que aquí defendemos debe llevar aparejada la inclinación hacia lo que podríamos denominar una actitud interculturalista (Gómez Lara, 2004: 93) como componente ineludible de las competencias cívicas en clave intercultural. En este sentido, al hablar de competencias interculturales y para la convivencia debemos referirnos a un conjunto de actitudes de la ciudadanía para desplegar ante la realidad del multiculturalismo social, basadas en valores éticos (igualdad, libertad, solidaridad, tolerancia, justicia,...) y otras competencias basadas en los derechos humanos; de ahí que podamos justificar el interculturalismo y sus competencias como parte intrínseca a la formación de una ciudadanía crítica. En todo caso, dichas competencias cívicas de corte intercultural deben reflexionar, entre otras, sobre las siguientes cuestiones: 
- Capacidad de análisis de otras culturas desde sus propios patrones culturales pero con el referente ético y crítico de los derechos humanos, de forma que no se dé paso a un relativismo cultural que puede acabar justificando prácticas culturales que atenten contra los derechos humanos y sí a una concepción de valoración y respeto a las diferencias.

- Capacidad de búsqueda del encuentro, lo que implica el ejercicio político que reniega de la etiqueta y la guetización al mismo tiempo que no teme el cambio inherente a la interacción, lo cual nos debe llevar también, por un lado, a entender ese encuentro como una oportunidad para el aprendizaje, y por otro, a desarrollar una concepción de la experiencia que se centre menos en el sujeto y más desde la confrontación con lo otro $u$ otros en marcos culturales diversos (Innerarity, 2001).

- Capacidad para el desarrollo de estrategias y tácticas para el trato y comprensión de lo diverso, lo que podríamos llamar 'traducción entre culturas' que nos ayudan a normalizar lo diferente transformándolo en una alteridad comprensible 0 al menos válida para la interlocución cultural.

- Capacidad de fomento de la curiosidad epistemológica, siguiendo la terminología de Freire (1997) y diferenciándola de una curiosidad ingenua, sino entendiéndola en el ámbito intercultural como una curiosidad crítica, enriquecida con las teorías, lecturas, hipótesis y reflexiones que permite discernir (por tanto elegir) los elementos exteriores que potencian aún más las culturas de referencia e interacción. La curiosidad epistemológica crece, se retroalimenta a medida que cada vez conoce más sobre otras culturas, otros pensamientos.

- Capacidad de comprensión y desarrollo, dentro de un marco con vocación intercultural, de la solidaridad como forma de conocimiento que se obtiene por vía del reconocimiento del otro/a, que sólo puede ser reconocido/a en tanto que productor de conocimiento. La construcción de un conocimiento multicultural en esta línea tiene, según Sousa Santos (2003: 31-32) dos dificultades: el silencio y la diferencia. El primero, debido a la destrucción e infravaloración de muchas formas de saber que la ciencia moderna y el capitalismo salvaje han arrastrado a la invisibilidad e incluso la desaparición. La segunda, incide en que sólo existe conocimiento multicultural $y$, por tanto, solidaridad en las 
diferencias, pero estas diferencias deben ser inteligibles y ahí volvemos a la necesidad de la traducción intercultural.

- Capacidad de diálogo como referente permanente en la construcción de lo intercultural. Como dice Bilbeny (2002: 152): "La sociedad es conversación, y cuanto más multicultural sea aquélla mejor deberá habituarse a prestar oídos a la diferencia en su interior y a entablar diálogo con ésta. (...) La interculturalidad nos hace ver de una vez que la 'ética del diálogo' es ética en diálogo, y que el discurso dialógico necesita el apoyo de las virtudes dialogales. El modelo del diálogo nunca está concluido, sino que se encuentra haciéndose permanentemente, y lo que lo mantiene así es la escucha real de las perspectivas que entran en diálogo".

- Capacidad empática, de forma que seamos capaces de identificar las vivencias del otro u otra e implicarnos en la búsqueda de alternativas desde la experiencia común en condiciones de equidad y desde la resolución pacífica de los conflictos inherentes a menudo desde la convivencia, sin dejar por ello de reconocer y valorar los contenidos transculturales que nos unen.

Todo lo anterior, indudablemente, supone un desafío para la educación, el cual es magníficamente reflejado por Bruner (1997) en el prólogo de su libro 'La educación, puerta de la cultura':

"La tarea de las nuevas generaciones es aprender a vivir no sólo en el amplio mundo de una tecnología cambiante y de un flujo constante de información, sino ser capaces al mismo tiempo de mantener y refrescar también nuestras identidades locales. El desafío es poder desarrollar un concepto de nosotros mismos como ciudadanos del mundo y, simultáneamente, conservar nuestra identidad local como mexicanos, zapotecos, españoles o catalanes. Posiblemente tal desafío representa para las escuelas, y la educación en general, una carga como nunca en la historia".

Esta responsabilidad implica que educativamente debemos tener muy presente de qué hablamos cuando lo hacemos de ciudadanía y educación cívica, así como de la necesidad de replantearnos permanentemente nuestra concepción de diversidad cultural y el tratamiento que hacemos de las diferencias desde un punto de vista social, político y pedagógico. Y para su puesta en práctica resulta imprescindible no caer en simplificaciones caducas 0 segregadoras, pues a veces podemos caer en el error de tratar la cuestión intercultural como algo homogéneo, descontextualizado y 
con pocas complejidades semánticas, y la realidad se empecina en mostrarnos lo contrario, ya hablemos desde las reivindicaciones de las minorías étnicas, la revitalización de culturas después de procesos de descolonización, las migraciones sean por motivos políticos, económicos, sociales o personales, los flujos informativos que transportan los medios de comunicación, la diversidad física o sensorial, el intercambio cultural, etc.

En todo caso, la construcción de una sociedad intercultural conlleva para la ciudadanía articular una serie de procesos de cambio que lleven a una definición de la misma al margen de limitaciones de corte nacionalista o excluyente, ajena al etnocentrismo y que facilite el intercambio, el mestizaje y la toma de referencia del estilo de vida cívico desde una perspectiva de derechos. La capacitación de la ciudadanía desde el ámbito intercultural debe suponer tanto la implicación política y social en orden a realizar aquellas transformaciones que acaben con las desigualdades enajenadas injustamente desde la diferencia, como una sensibilización y toma de conciencia con respecto a la sustantividad de que todos y todas seamos educados en la diversidad desde la equidad. La educación adquiere así un papel relevante, vinculado por esa finalidad básica de formación ciudadana del sistema educativo con un sentido de responsabilidad política pública.

En este sentido, hay que destacar cómo los sistemas educativos públicos deben tener como prioridad consustancial a su propio ser no dejar ninguna cultura fuera ni menospreciada, reconociendo la identidad como derecho y la redistribución como principio (Fraser; Honnett, 2003). Para ello hay que defender en la acción educativa, la construcción de la ciudadanía como ámbito de participación común y solidaridad. Conciliar la dialéctica entre identidad cultural y diversidad es, pues, nuestro reto mayor y eso provoca la necesidad de que nos refiramos a la educación cívica intercultural, es decir, a la necesidad de adjetivar a la educación para la ciudadanía para visibilizar su sentido social y político en un contexto multicultural. Esto pudiera entenderse como redundante en algunos aspectos, pero sucede aquí como con las cuestiones de género y otras más vinculadas a la igualdad y los derechos, que resulta básico particularizar y desmenuzar su condición para que educativamente ejerza su fuerza como elemento no excluyente, pudiendo así también diferenciarse de la concepción ciudadana liberal vinculada exclusivamente a la pertenencia comunitaria 0 Estatal. 
Desde lo anterior, debemos considerar la educación intercultural como aquélla vinculada a democracias intensamente pluralistas y participativas, ya que supone el recíproco reconocimiento igualitario de todos y todas como sujetos de derechos en cuanto que sujetos con capacidad de participación política en un contexto convivencial. Además, conlleva la asunción compartida, desde las diferentes tradiciones de origen $y$ comunidades de pertenencia, de los valores éticos vinculados a los derechos humanos como valores comunes, y la confluencia en el espacio público como espacio de todos y todas donde no se trata de forjar únicamente buenos malagueños/as, andaluces/as, españoles/as o europeos/as, que sería seguir el juego de la identidad ciudadana monocultural, sino formar ciudadanías responsables desde la convivencia, con identidades compartidas y diversas, en defensa del pluralismo como condición indispensable de la libertad en una sociedad civil verdaderamente democrática. Por lo tanto: "El desafío educativo implica desarrollar la capacidad de construir una identidad compleja, una identidad que contenga la pertenencia a múltiples ámbitos: local, nacional e internacional, político, religioso, artístico, económico, familiar, etc. Lo propio de la ciudadanía moderna es, precisamente, la pluralidad de ámbitos de desempeño y la construcción de la identidad a partir precisamente de esta pluralidad, y no de un solo eje dominante y excluyente" (Tedesco, 2000: 86).

La educación pública surgió, entre otras cuestiones, para abordar esa formación de la identidad ciudadana, pero lo hizo en un contexto liberal donde el 'oficio' de la ciudadanía estaba destinado a una comunidad más o menos homogénea y bajo unos patrones prefijados en una idea de nación o pueblo ya estructurada, por lo que tenía en el fondo un carácter socializador cercano a la reproducción. Por ello la educación pública actual debe dar un paso más desde la inclusión, haciendo que la educación cívica, en el sentido más amplio, se realice en condiciones de apertura a todo el alumnado sin excepción, conjugando el respeto y la valoración de la diversidad sociocultural $y$ las diferencias individuales $y$ contribuyendo, así, a una socialización intercultural (Bolívar, 2004). Dicha socialización se debe dar desde la educación pública en base a la lucha contra la exclusión y una formación cultural diversa que permita analizar críticamente e intercambiar propuestas sociales y políticas en contexto, donde se parte de un sentido de la inclusión como "igualación de los discriminados y a la incorporación de los 
marginados sin integrarlos en la uniformidad de una comunidad homogeneizada" (Habermas, 1999: 118). Y todo ello implica presencia de la perspectiva intercultural para ser llevado a cabo.

Así, desde el punto de vista educativo, lo intercultural pretende promover relaciones dialógicas e igualitarias entre personas y grupos que pertenecen a mundos de significados distintos e interviene mediando en los conflictos presentes ineludiblemente en los procesos convivenciales de estos procesos, sin ignorar ni las relaciones de poder dadas, sino identificándolas y estableciendo recursos desde la formación cívica para la generación de estrategias que trabajen dichos conflictos. Además, no debemos olvidar que se trata de un proceso permanente, siempre inacabado, marcado por la deliberada intención de promover relaciones democráticas entre personas y grupos de identidades culturales distintas y no solamente una coexistencia pacífica, rompiendo con una visión esencialista de las culturas y de las identidades culturales y dotándolas de capacidad de apertura.

La educación intercultural debe verse, entonces, como un modo de conciliar el pluralismo y la configuración identitaria que supere la tradición cívica de la educación pública tradicional, que ha legitimado una perspectiva cultural educativa dominante bajo una concepción universalista que enmascara posiciones homogeneizadoras y excluye o invisibiliza otras formas de ser y estar en el mundo. En respuesta a esto, vamos a partir a continuación de las Directrices de la UNESCO sobre la Educación Intercultural (2006), en las cuales se desarrollan estos tres principios:

\section{Principio I}

La educación intercultural respeta la identidad cultural del educando impartiendo a todos una educación de calidad que se adecúe y adapte a su cultura.

\section{Principio II}

La educación intercultural enseña a cada educando los conocimientos, las actitudes y las competencias culturales necesarias para que pueda participar plena y activamente en la sociedad.

\section{Principio III}

La educación intercultural enseña a todos los educandos los conocimientos, actitudes y las competencias culturales que les permiten contribuir al respeto, el entendimiento y la solidaridad entre 
individuos, entre grupos étnicos, sociales, culturales y religiosos y entre naciones.

Partiendo de dichos principios, y relacionándolos con la educación cívica, vamos a desarrollar una serie de puntos a modo de prioridades para su consecución en el marco específico del desarrollo de la acción necesaria para transitar hacia una educación intercultural:

- Identificar las representaciones de la alteridad presente y ausente que todos y todas construimos, de manera que los procesos educativos cívicos interculturales favorezcan la concientización, que diría Freire, de esas representaciones del otro - la otra diferente, las cuales nos hacen situarnos en nuestro contexto concreto y nuestra forma de ver el mundo desde nuestras percepciones y comprensión de la diversidad.

- Profundizar en la configuración de los prejuicios y discriminaciones presentes en nuestras sociedades, evitando su naturalización y reivindicando la lucha contra los mismos en tanto que simplificaciones segregadoras de la realidad con fuertes cargas cognitivas, culturales y emocionales a las que desde la educación debe darse respuesta a través del análisis crítico de situaciones y hechos concretos desde una perspectiva dialógica.

- Cuestionar el status quo de ciudadanía basada en una perspectiva monocultural o etnocéntrica. Esto nos debe llevar a la visibilización de la pluralidad cultural para abrir espacios de construcción de nuevos desarrollos de la ciudadanía desde el referente de la interculturalidad, así como reconocer nuestra propia identidad cultural desde una óptica inclusiva y siendo conscientes de que vivimos permanentemente en un cruce de culturas desde el que reinventamos nuestras identidades.

- Visualizar la alteridad presente en nosotros y nosotras, es decir, ser capaces de mirarnos siendo conscientes de que lo que somos y nuestra historia lo es desde la interrelación con la de los y las demás, por lo que la educación cívica intercultural debe ayudarnos a observarnos a nosotros y a nuestras relaciones de otra manera, más plural y dialéctica, y un buen instrumento para ello son las historias de vida concretas o las aportaciones de los medios de comunicación y las TICs en este sentido.

- Conjugar la promoción de políticas de igualdad (equidad) y políticas de identidad (reconocimiento) tanto a nivel macro como en la micropolítica de la acción educativa, fomentando así una ciudadanía activa, el empoderamiento de las culturas no 
hegemónicas y unas prácticas educativas sustantivas vinculadas con la propia praxis de los derechos humanos de primera, segunda y tercera generación.

- Buscar la cooperación entre los diversos ámbitos educativos, formales y no formales, en beneficio de una educación pública de calidad que dé respuestas a los desafíos cívicos de nuestras sociedades multiculturales. Para ello no son suficientes didácticamente momentos puntuales o específicos de tratamiento más o menos artificial de las alteridades culturales, sino que se requiere además de la promoción de experiencias de diálogo en profundidad con el otro cultural y de asunción de su papel social igualitario desde las diferencias que nos legitiman para la convivencia.

En definitiva, la educación intercultural no deja de ser un proceso complejo y fascinante de construcción de otra manera de ver y poner en práctica la educación pública que parta de la problematización de la hegemonía excluyente para promover así el reconocimiento y la valoración de las diferencias culturales y nuestras relaciones con el otro/a de manera que, con el referente de los derechos humanos, nos permita el diálogo para generar un proyecto común de convivencia donde todas y todos seamos partícipes y protagonistas.

\section{Bibliografía}

Bauman, Z. (2007). Confianza y temor en la ciudad. Vivir con extranjeros. Barcelona: Arcadia.

Bilbeny, N. (2002). Por una causa común. Ética para la diversidad. Barcelona: Gedisa.

Bruner, J. (1997). La educación, puerta de la cultura. Madrid: Visor. Madrid: Morata.

Fraser, N.; Honneth, A. (2006). Redistribución y reconocimiento.

Freire, P. (1997). A la sombra de este árbol. Barcelona: El Roure.

García Canclini, N. (2005). Diferentes, desiguales y desconectados. Mapas de la interculturalidad. Barcelona: Gedisa.

Giroux, H. (2001). Cultura, política y práctica educativa. Barcelona: Graó.

Gómez Lara, J. (Ed.) (2004). La escuela intercultural: regulación de conflictos en contextos multiculturales. Madrid: La Catarata.

Habermas, J. (1999). La inclusión del otro. Barcelona: Paidós.

Innerarity, D. (2001). Ética de la hospitalidad. Madrid: Península.

Martínez de Bringas, A. (2007). Interculturalidad en tiempos globales: el reto de los derechos de las mujeres migrantes. En E. S. Vila 
Merino, (Coord.), Pedagogía de la alteridad. Interculturalidad, género y educación, 27-42. Madrid: Popular.

Sousa Santos, B. (2003). Crítica de la razón indolente. Bilbao: Desclée de Brower.

Tedesco, J. C. (2000). Educación y sociedad del conocimiento. In Cuadernos de Pedagogía, 288 (2000) 82-86.

${ }^{1}$ In search of a common language in Education: what do we mean when we talk about interculturality?

2 Doctor.

Universidad de Málaga (España).

Email: eduardo@uma.es 
